\title{
Move to literacy: fanning emergent literacy in early childhood education in a pedagogy of play
}

\begin{abstract}
A literate child is one who is able to read, write, speak and listen. Literacy begins at birth, and continues steadily as children develop. The explicit processes that form emergent literacy are for example, phonemic awareness, letter and word recognition, vocabulary enrichment and structural analysis. These literacy practices are well documented and articulated. But how these practices and the knowledge, skills, attitudes and values (KSAVs) that underpin them are best acquired by young children is contested. This paper argues that an early childhood education (ECE) approach, which fans literacy, should follow a quality play-based approach that embraces a pedagogy of play that foregrounds how children learn through play, and how teachers teach through play. In combining two constructs 'pedagogy' and 'play', we propose an approach that is underpinned by movement and other appropriate learning activities, which support the development of perceptual-motor behaviours and sensorimotor integration in a pedagogy of play. We argue that perceptual-motor behaviours and sensorimotor integration are the 'invisible' pathways to literacy. They provide young children with many and varied, incidental, implicit and explicit learning opportunities. A more informal, play-based approach towards teaching and learning appears to be a successful way of nurturing literacy processes.
\end{abstract}

Keywords: pedagogy of play; sensorimotor integration; perceptual motor development; early literacy; learning dispositions

Mrs Lorayne Excell \& Mrs Vivien Linington, University of Witwatersrand. E-mail: lorayne. excell@wits.ac.za\&vivien.linington@wits.ac.za.

South African Journal of Childhood Education | 2011 1(2): 27-45 |ISSN: 2223-7674 |৫ UJ
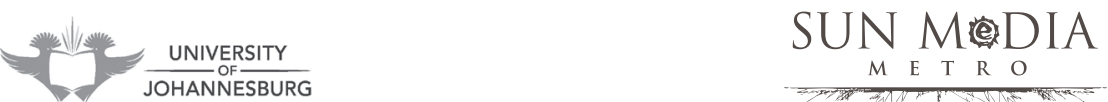


\section{Introduction}

A literate child is one who is able to read, write, speak and listen (Hill, 2006). Literacy begins at birth, and continues steadily as children develop (Hill, 2006). The explicit processes that form the road to literacy are, for example, phonemic awareness, letter and word recognition, vocabulary enrichment and structural analysis. These literacy practices are well documented and articulated (Heilman, Blair \& Rupley, 1994; Hill, 2006). But how these practices, and the knowledge, skills, attitudes and values (KSAVs) that underpin them, are best acquired by young children is contested terrain.

There is an increasing body of knowledge that posits that initial exposure to literacy practices should not be done through formal explicit instruction. As Werner (in Crain, 2005) emphasises, preschool teachers should not focus on any specific intellectual process, such as literacy, without considering the broader context out of which it develops. Werner argues that we first need to consider how literacy can develop out of rich experiences with oral language and other symbolic activities. Providing young children with many, varied incidental and implicit learning opportunities through a more informal play-based approach towards teaching and learning appears to be the most successful way of nurturing the literacy processes (Riley, 2003).

Yet despite this knowledge claim, there appears to be an increasing emphasis on more formal literacy practices in preschools including the Grade $\mathrm{R}$ year. Schoolbased observations in Gauteng (WsoE, 2009) show that there is growing emphasis on worksheets and formal literacy instruction. And there is no reason to presume that these findings differ for the rest of South Africa (SAIDE, 2010). The teaching of (formal) literacy skills has become 'classroom bound' with an overemphasis on paper and pencil tasks, as well as drilling and rote learning, which is often decontextualised and carries no meaning for the children involved in these activities. This, in turn, has led to decreased opportunities for children to experience appropriate fine motor and gross motor movement, be this through creative art activities, playing with educational games or enjoying outdoor free-play. Is this in the best interests of the young child and later formal literacy practices? We argue to the contrary.

Recent research evidence (Gallahue \& Donnelly, 2003; Ayers, 2005; Isbell \& Isbell, 2007) shows unequivocally that children's successful academic learning is enhanced when they are given sufficient and appropriate opportunities to move. It is through movement that the essential perceptual-motor skills and concepts ${ }^{1}$, and sensorimotor integration (those implicit processes and 'invisible' pathways that underpin literacy learning) are best developed. In addition, these 'invisible' pathways provide the foundations upon which formal literacy instruction is based.

Yet, there appears to be a dearth in emergent and early literacy research into the role of movement and the perceptual-motor skills and concepts, as well as the 'invisible' pathways that underpin literacy and its four major components; listening, speaking, reading and writing. Through this paper we aim to heighten awareness of the importance of early childhood education (ECE) pedagogy that promotes, through movement activities (as well as other activities), the development of these 'invisible' 
pathways, and thus provides the fundamental building blocks on which more formal literacy practices depend.

Our expertise is in ECE. We are neither biokinetisists nor neurophysiologists. The rationale behind this paper emanates from our growing concern over the increasing formalisation of ECE programmes despite overwhelming evidence illustrating the value of play-based programmes that offer appropriate movement opportunities. Are there not, we ask, other ways of conceptualising ECE pedagogy that will offer alternative forms of practice to ECE teachers who are following more formal programmes "because we have to get children ready for the demands of Grade 1", and because "there is a increasing demand to teach children the three Rs - reading, writing and arithmetic?" (WSoE, 2009).

We hope that, by setting out these pathways more explicitly and showing how they can be developed through the implementation of appropriate ECE pedagogy, we will heighten awareness of the value of appropriate and relevant ECE learning programmes.

Therefore, in this paper we begin by defining what comprises these implicit processes or invisible pathways. We, then, argue that they are best nurtured through a more informal play-based approach to early learning that acknowledges the importance of movement, as well as other play-based activities for maximising learning in the young child. Thirdly, we suggest that to meet the challenges of teaching and learning in a $21^{\text {st }}$ century context, a particular form of play, a pedagogy of play (Wood, 2009) can best act as a catalyst for fanning the emergence of the perceptual-motor skills and concepts, and the simultaneous development of sensorimotor integration. This integration is integral to academic achievement and appropriate learning behaviours (Ayers, 2005; Isbell, C. \& Isbell, R., 2007). In short, for the preschool child play and movement are critical to the development of literacy. And a teacher who understands this will be an integral and effective part of the child's quest to acquiring literacy.

\section{The 'invisible' pathways to literacy}

One of the first ways children learn is through their senses, that is, as they hear, see, smell, taste and feel. Information gathered through the senses, namely, sensations, elicits an electro-chemical response. According to Ayers (2005), the sensations we experience provide three different sets of information. The first set tells us where our body is in space and how it is moving. This set of information is provided in two ways. Firstly, by proprioceptors, which process the input about body parts and the body's position in space. This information is received through the muscles, ligaments and joints. For example, we see a step and know we have to move our lower body appropriately. And secondly, by the vestibular receptors, which process input about movement, gravity and balance and receive this input through the inner ear (Kranowitz, 1998).

The second set of information comes from the exteroceptors, which are linked to the five senses and enable us to respond to sensations or input coming in from outside 
the body. For example, we see a dog snarling and back away or we hear a baby cry and run to comfort the child.

The third set of information comes through the interoceptors, which alert us to sensations coming from the visceral (internal) organs in the body. If, for example, you feel your pulse you are able to pick up the rhythm of your heartbeat.

When sensations from these three information sources are successfully integrated, the brain can use these sensations to perceive and provide an appropriate motor response or action. In other words, the senses enable us to draw in information from a variety of sources, to interpret this information (or sensations) in the brain and then respond appropriately. For example, when a child is riding a bicycle, s/he sees a road sign, interprets it as a warning to slow down and applies the brake.

The impressions gained through the senses, therefore, give rise to meaning and subsequent action (Arnheim \& Pestolesi, 1978). A child's ability to interpret input from the senses ${ }^{3}$, and respond through movement is inextricably linked to their ability to understand and control their environment effectively (Lundsteen \& Tarrow, 1981). This assertion illustrates the inseparable nature of the relationship between cognitive and motor development. Gallahue, Werner and Luedke (1975, p. viii) capture this notion succinctly when they comment "as the child learns to move he moves to learn".

The idea that body movement is a fundamental component in young children's learning is not new (Gerhardt, 1973, p. xi), but research (WSoE, 2009) showed that in Grade R movement is being sidelined to meet the more formal pedagogical demands. And this amounts to a lost opportunity to develop gross and fine motor skills, as well as other neuro-physical aspects of learning, since through the exploration of movement the child is able to adjust to, understand and ultimately master his environment (Gallahue, Werner \& Luedke, 1975, p. 4). The young child must overcome the pull of gravity in order to sit and stand, he must develop his basic locomotor abilities so he can move through space, and he must be able to handle objects to which he relates (Gallahue et al., 1975, p. 42). As Gabbard (2008), Robinson and Goodway (2009) note, mastery of fundamental movement skills in early childhood are the building blocks for more complex movement, and play an important role in the overall development of school readiness.

In the early years gross motor skills are necessary for movement, as well as to stabilise and control the body. Through gross motor skills children improve their posture, sense of balance and co-ordination. This, in turn, enables children to develop fine motor skills that are essential for success during the subsequent school years (Gallahue \& Ozmun, 1998; Gallahue \& Donnelly, 2003). It is through the successful acquisition of gross and fine motor skills that the different perceptual-motor behaviours become refined. 


\section{Perceptual-motor development, sensorimotor integration}

Perceptual-motor development, which results in a range of perceptual-motor behaviours, is a process that starts at birth (if not before) and increases in complexity during the formative years. By the age of six or seven the perceptual-motor behaviours are generally refined (Gallahue \& Donnelly, 2003). There are three broad categories of perceptual-motor behaviours all of which are closely linked to the development of early literacy. The three categories are:

- Spatial awareness and orientation behaviours, which refer to children's understanding of their bodies and what their bodies can do, and includes body awareness and body image that are, of course, closely related. Spatial awareness and orientation behaviours also embrace a child's awareness of their position in space in relation to other objects, the ability to cross both the vertical and horizontal midlines ${ }^{4}$, and to understand the concepts of directionality and laterality.

- Sensory awareness behaviours, which refer to children's ability to respond to sensations perceived ${ }^{5}$ through the five senses. For successful academic learning, the development of two sensory motor behaviours in particular is crucial, namely auditory and visual perceptual-motor awareness. Examples of these perceptualmotor behaviours include visual and auditory memory (being able to remember what has been seen or heard), matching (being able to recognise when images or sounds are the same), discrimination (being able to tell the difference between images or sounds), and closure (seeing or hearing, for example, the first part of an image or sound and then being able to envisage the image or sound as a whole). Listening is, of course, another important auditory perceptual-motor behaviour, which children should acquire.

- Temporal awareness, which refers to children's ability to develop an inner and outer sense of time. This includes co-ordination and rhythmic movements.

Figure 1 outlines perceptual-motor development and behaviours, and, in the process, illustrates how the acquisition of these behaviours provides a foundation on which more formal literacy learning can be based. 


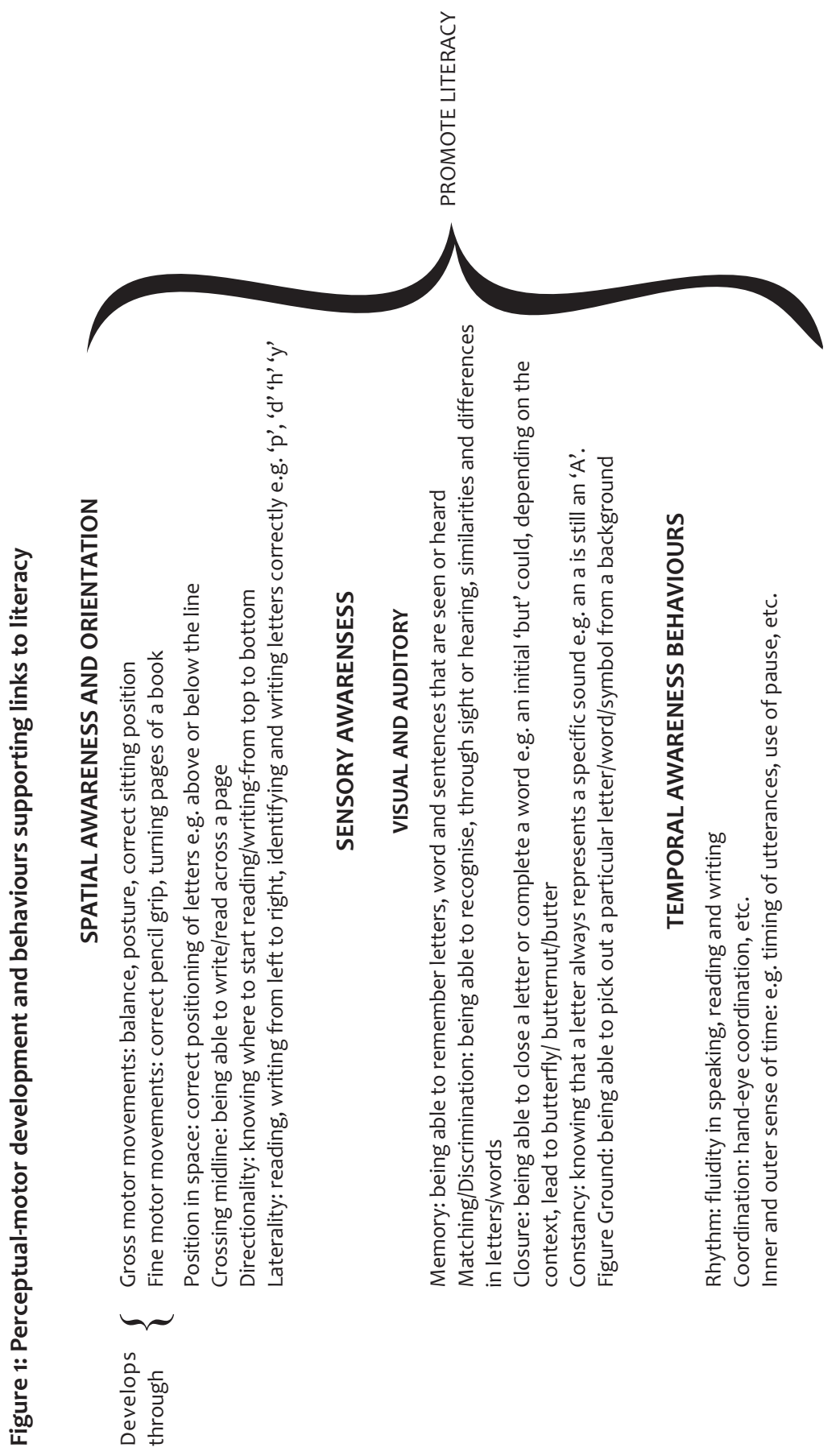


As already mentioned, perceptual-motor behaviours underpin the successful acquisition of literacy (and other academic) knowledge, skills, attitudes and values. But the mere acquisition of these perceptual-motor behaviours is not enough to enhance academic learning. Children also have to develop the ability to integrate these behaviours to ensure that their body functions as a smooth flowing unit, when responding to different sensations. Handwriting, for example, is dependent on this integration. In Grade 1, a teacher might demonstrate the formation of the letter 'a' on the board. For the learner the process should, then, proceed as follows:

- Listen to the teacher as she explains the steps required to form the letter itself (auditory awareness);

- $\quad$ Observe how the teacher forms the letter on the board (visual awareness);

- $\quad$ Process these two sources of information in the brain; and

- $\quad$ Respond through appropriate movement, i.e. form the letter themselves in their books. This is a motor response, which is dependent on a number of different skills; gross and fine motor co-ordination (itself an inextricable part of the successful sensorimotor integration), auditory and visual cues (such as memory), hand-eye co-ordination, and spatial awareness and orientation (Charlesworth, 2004).

The successful formation of the letter ' $a$ ', therefore, draws on the combination of all aforementioned factors plus others, which we have not listed or discussed here.

This ability to integrate different perceptual-motor behaviours, such as those described above, is called sensorimotor integration, and refers to the process of organising sensory inputs (sensations) so that the brain produces a useful/meaningful body response and also useful perceptions, emotions and thoughts. Sensory integration sorts, orders and eventually puts all sensory input together into a wholebrain function (Ayers, 2005).

Figure 2 provides a diagrammatic representation of the cyclic nature of sensorimotor integration and its fundamental link to the learning of literacy. 
끌

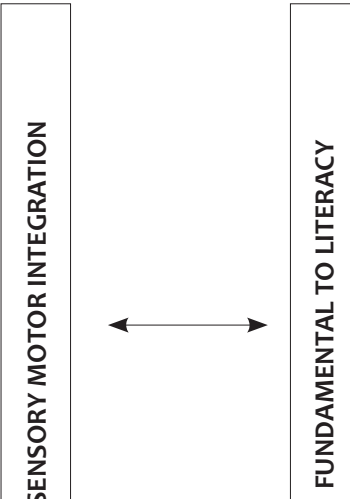

$\frac{1}{+0}$
.0
$\frac{0}{0}$
0
0

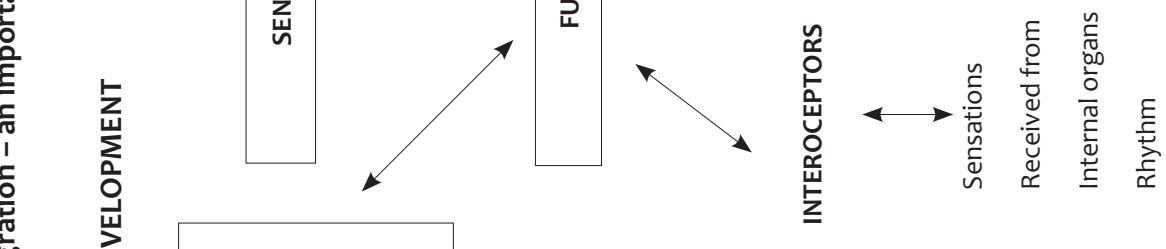

夏
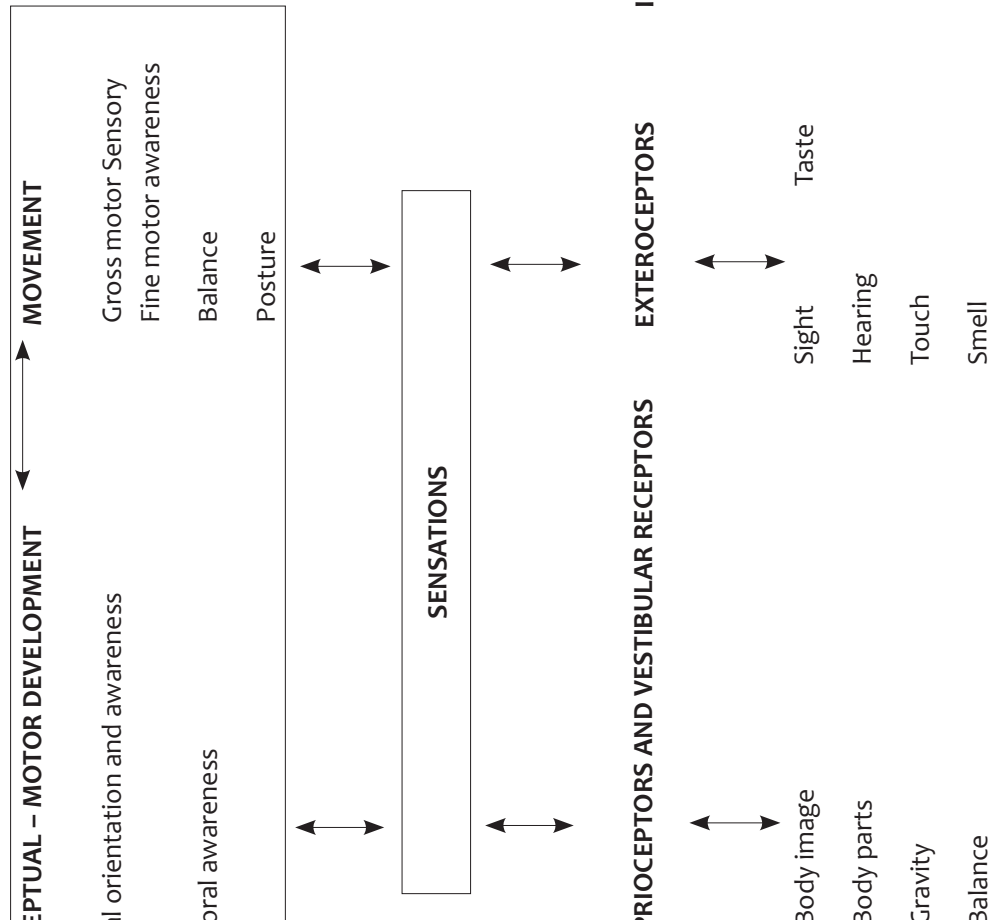

竞

ป气

롭

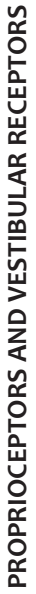

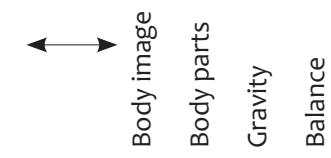

닌

인 
Sensorimotor integration is an unconscious process of the brain that is geared to organising information detected by the senses (taste, touch, sight, hearing, smell, movement, gravity and position). It gives meaning to what is experienced by sifting through all the information, and then selecting what to focus on, for example, listening to the teacher and not the noise in the playground. Furthermore, it allows us to act or respond to the situation in a purposeful manner.

The acquisition of perceptual-motor behaviours, and successful sensorimotor integration are extremely complex processes, which appear to be best acquired through appropriate movement activities (Gallahue \& Donnelly, 2003; Ayers, 2005; Isbell \& Isbell, 2007). This contention is further supported by findings of research conducted on the brain by Bransford, Brown and Cocking (1999). In recent years findings from brain research confirm the neural plasticity of the young child's brain; and illustrate that appropriate experiences, which elicit adaptive responses, enhance the interconnectivity of neurons. Appropriate movement experiences stimulate and develop the neural pathways, which allow us to take in information from the world (sensations), interpret it (in the brain) and then to respond (motor movements). Appropriate learning experiences enhance the interconnectivity between the neurons (different nerves), and establish many different neural pathways. The optimal arranging of neural pathways, through appropriate learning experiences, promotes sensorimotor integration, including the development of perceptual-motor skills and concepts, and underpins academic learning and social behaviours, such as literacy behaviours. We are not suggesting that development can, or should, be accelerated through movement, as this is a highly contested issue (Dahlberg, Moss \& Pence, 1999; Mac Naughton, 2003; Penn, 2008). Instead, we are arguing that appropriate movement activities have the potential to maximise learning in young children, because of the role movement plays in the development of the invisible pathways.

Consequently, the more opportunities/experiences that children have to develop these invisible pathways and neural interconnectivity, the more effectively the neural pathways are established with positive consequences for later academic learning. And many of these opportunities and experiences are provided through appropriate movement and play opportunities.

In short, through exploration and guided experiences, fundamental movement patterns become an inherent part of games, skills, rhythms, and self-testing activities. For this to happen, it is essential that children experience many different types of movement and these experiences, we suggest, might best be offered through a pedagogy of play.

\section{A pedagogy of play}

Children's learning is best supported through a play-based, informal approach towards teaching and learning that promotes the holistic development of children (Pellegrini, 1991; Spodek, Saracho \& Davis, 1991; Moyles, 1989; 1994; Gordon \& Browne, 2008). As Riley (2003, p. xx) writes "play-based activities appear to meet all [...] educational 
aims." Hence, it could be argued that there is a general consensus that high-quality, well-planned and developmentally appropriate experiences will use play to promote learning (Pellegrini, 1991; Pramling-Samuelsson, 2005; Pramling-Samuellsson \& Carlsson, 2008).

This assertion was acknowledged by Vygotsky who saw play as a leading factor in child development. He argued, in fact, that play, like schooling, also operated in advance of development. "In play a child is always above his average age, above his daily behaviour, in play it is as though he were a head taller than himself" (Vygotsky, 1978, p. 129).

Optimising play and realising the potential of a play-based curriculum in the early years is one of the ongoing challenges that ECE faces in this millennium, especially as the pervasive worksheet culture appears to be tightening its grip on Grade $\mathrm{R}$ in particular (WSoE, 2009). The challenge that this 'formal creep' presents resonates with Wood's (2009, p. 29) assertion that:

\section{Although contemporary curriculum models endorse play within integrated pedagogical approaches, achieving good quality play in practice remains a considerable challenge, particularly $[\ldots]$ where teachers face competing demands for accountability, performance and achievement, and competing notions of what constitutes effective teaching and learning.}

Following the articulation of this challenge, more contestation and heated debates have emerged. As Wood (2009, p. 27) notes "linking play and pedagogy becomes a contentious issue because of the ideological commitment to free play." This contention is due in part to disparate understandings of the constructs 'play' and 'pedagogy' and the fact that some ECE educators see these two terms as dichotomous. As Rogers (2011) states, the words play and pedagogy, taken separately, are viewed in educational discourse as disparate. Each word has its own particular meaning and its own particular form of power that impact teaching and learning. Furthermore, teachers' understandings of pedagogy usually take as their starting point the adult's role in providing an environment and strategies that support the process of teaching and learning (Rogers, 2011).

One way of addressing this perceived disjuncture between pedagogy and play, and maximising the power inherent in both terms, is to rethink our understanding of pedagogy in relation to the characteristics and benefits of play (Wood, 2009; Rogers, 2011). We would agree with their position as these two terms, when interwoven, could enrich learning and teaching. But what is a pedagogy of play?

A 'pedagogy of play' is defined by Wood (2009) as:

The ways in which early childhood professionals make provision for play and playful approaches to learning and teaching, how they design play/learning environments, and all the pedagogical decisions, techniques and strategies they use to enhance learning and teaching through play (p. 27).

This definition places the teacher in a specific role, which involves the planning and implementation of an interactive, learning environment that offers children challenging and stimulating choices that, in turn, promote holistic development. Through a 
pedagogy of play, teachers can provide opportunities for free play and spontaneous movement activities, as well as guided movement experiences designed to support specific aspects of gross motor, fine motor and perceptual-motor development, which, in the end, facilitate emergent literacy in young children.

For Vygotsky (1978) play is a crucial area in development. He recognised that children learn through social relationships and interactions. In fact he saw play as creating a zone of proximal development in which children function at a higher level than they do during everyday tasks. He believed that both adults and more skilled children can nurture this learning by supporting, explaining and extending the experience further. Such acts could be seen as purposeful and this concurs with Wood's claim that in a pedagogy of play, learning and teaching through play, is purposeful. As Wood, (2009, p. 27) comments:

\section{Play is sustained through reciprocal and responsive relationships, and is situated in activities that are socially constructed and mediated. While children's interests remain central to curriculum planning the subject disciplines enrich and extend the children's learning.}

This assertion again places the teacher in a critical role. For a creative, flexible ECE teacher focused on developing early literacy in the context of whole child development, a pedagogy of play can open new literacy pathways. In fact, a pedagogy of play is almost limitless in its potential to optimise learning. But the optimisation of that potential lies, to a large degree, with the teacher and his/her interpretation of curriculum. As Wood (2009, p. 27) notes, a curriculum informed by a pedagogy of play can include the ways in which children "act as playful pedagogues in their selfinitiated activities". It is this notion of playfulness that should be a central informing source as ECE teachers experiment with alternative strategies for implementing an effective play-based curriculum in early years education; a curriculum that foregrounds movement and the co-construction of knowledge.

A pedagogy of play is not rigid. It will have multiple forms and types. But there are some constants particularly in relation to the element play. As Wood (2009) contends:

Good quality play is linked to positive learning outcomes in the cognitive, emotional, social and psychomotor domains, and in the six areas of learning (p. 28).

The six areas to which Wood refers are drawn from the United Kingdom's Early Years Foundation Stage (EYFS), which is made up of areas of Learning and Development. These are: 
- $\quad$ Personal, Social and Emotional Development

- Communication, Language and Literacy

- Mathematics (Problem Solving, Reasoning and Numeracy)

- Knowledge and Understanding of the World

- $\quad$ Physical development

- $\quad$ Creative Development

- (Early Years Foundation Stage, 2007)

An ECE teacher planning a curriculum would need to take cognizance of all six areas, and the potential of these areas to fan both literacy and child development as a whole. Knowledge of the latter is essential in the design of appropriate learning activities, but on its own is not enough. As Walsh (2005, p. 40) warns, a deep knowledge and understanding of "development is necessary but not sufficient." We should also heed Penn's (2008) argument that neuroscience and physiology has provided us with little definitive knowledge about how learning is enhanced. Teachers should also be aware that play is unlikely to be universally effective, or desirable as a path to promoting learning in all contexts for all children (Rogers, 2011). In other words, play is not always positive. ECE teachers need to ask themselves who does play privilege and who does it marginalise ${ }^{6}$ ? (Mac Naughton, 2003). Literacy is grounded in social, cultural, historical and political practices (Gee, 1996 in Larson \& Marsh, 2005). So too is play (Anning, Cullen \& Fleer, 2008). A $21^{\text {st }}$ century context requires teachers to take cognisance of these claims and practices when implementing an ECE curriculum.

All the above claims highlight the necessity of an ECE teacher's rich knowledge base. In short, physiology, brain research, learning theories, whole child development, understandings of play and curriculum planning should all be considered when conceptualising a pedagogy of play that enables the optimisation of every child's literacy or literacies potential. We use the term literacies for, as Heath (in Whitehead, 2010) points out, children participate quite naturally in many 'literacy events' out of school as part of their social and cultural life. These events, for example a shared attempt by a family to make sense of the instructions for assembling a bench, form the basis of 'school literacy'. As Whitehead (2010, p. 154-155) asserts:

Literacy is not just a performance skill with the written system of the language but a cognitive tool that transforms our capacity for self-reflection, mental reorganization and evaluation. Writing is not just for conveying information and instructions, nor is it just for sharing pleasure and messages - writing is for thinking.

It is this understanding that should, we argue, inform a pedagogy of play. For this form of play is one of the precursors of writing, and should therefore present a rich language environment where playfulness with story and (where appropriate) rhyme is constantly apparent. 
The above claims point to an increased focus on the interactive roles of adults (as they engage with children to co-construct knowledge) to promote, challenge and support play that is both socially and conceptually complex. It is not only children who should act as playful pedagogues. In socio-dramatic play, a teacher can identify 'teachable moments' as they spontaneously emerge and use these moments to coconstruct new understandings with children, as well as enrich vocabulary. As Wood (2009, p. 29) points out, indicators of effective pedagogy in ECE entail; "opportunities for co-construction between children and adults, including 'sustained shared thinking', joint involvement in child- and adult-initiated activities and informed interactions in children's self-initiated and free-play activities".

The realisation of a pedagogy of play would present ECE teachers with a demanding new set of challenges. Included in these would be the need for a South African based reconceptualisation of the terms 'pedagogy' and 'play'; a reconceptualisation that demonstrates insight into how these two notions can operate in unison to promote literacy. The conceptualisation of the united pair (pedagogy and play) is essential because, as Wood (2009) points out, while there is substantial evidence of learning through play there is less evidence of teaching through play. Therefore, we suggest, that possible manifestations of a pedagogy of play in the South African context should be a priority research area. As an inaugural step, this paper considers a pedagogy of play in the context of literacy that might open up a space for intellectual debate on the details of a practical realisation of a play-based pedagogy.

A starting point for this debate could come from the definition of a pedagogy of play. The phrase "... the ways in which early childhood professionals make provision for play and playful approaches to learning and teaching ..." (Wood, 2009, p. 27) complements Whitehead's (2010) assertion that:

Literacy progress should be the dominant and joyful focus of the early years curriculum and it should be at the centre of the genuine partnership between early years settings, schools and parents (p. 138-139).

The words 'joyful focus' and 'partnership' form an integral part of the approach to early literacy set out in this paper. Children find joy in movement; both spontaneous movement, which is often part of free play, and more structured movement activities, such as movement and music rings, in which teacher guidance is more explicit. In teacher guided activities creative and problem solving elements could be introduced. For example, the teacher could ask children to collaboratively explore different ways of using their bodies to represent specific letters of the alphabet. In all these instances the type of programme adopted by the teacher is pivotal. It can either enhance or reduce literary-enriched learning opportunities.

\section{Enhancing emergent literacy}

Wood (2009) points out that research in the field of play and literacy has been conducted from multiple perspectives, and has generated strong evidence of links between developing literacies and play activities (Marsh, 2005; Roskos \& Christie, 
2000 in Wood, 2009). Wood (2009, p. 29-30) asserts "there is substantial evidence that through play children demonstrate improved verbal communication, high levels of social and interaction skills, creative use of play materials, imaginative and divergent thinking skills and problem-solving capabilities". Furthermore, she contends, "play and playful forms of activity potentially lead towards increasingly complex forms of knowledge, skills and understanding, particularly in the cognitive and social domains" (p. 30). So how does this promote literacy?

While children are having fun, and this frequently happens during play and movement activities, they are at their most receptive to taking in sensations, and to responding to them. During these activities they are refining their fundamental motor skills, and, at the same time, establishing perceptual-motor behaviours, which we have argued are fundamental building blocks on the road to literacy.

But this is only one aspect of literacy acquisition. As young children set out on the road to literacy there are other clear signposts that point the way. There are letters, sounds, words, pictures, prediction and problem solving, and a wealth of other pointers. There are shared 'literacy' encounters, picture books, story time and language play. Literary-enriched play and 'mediatable moments'7 occur spontaneously during the early childhood school day, often in the context of play. It is the utilisation of these moments plus, of course, knowing when to step in and when to stand back, that can promote literacy.

The literacy potential in ECE is multi-faceted. In free play, routines, and rings ${ }^{8}$ the potential for developing literacy is there. Its development should become each teacher's personal, and professional responsibility.

The complexity of his/her task is captured in the words of Whitehead (2010) who states:

Experienced professional teachers of early literacy have to interpret the many complex findings of research and clarify the issues in discussions with other professionals and young children's families. Factors that need to be considered include, current knowledge about the brain and children's different developmental stages, learning styles, cultural, social and home literacy experiences (p. 138).

South Africa's language diversity, while a rich resource poses many challenges. The adoption of a multi-modal pedagogy ${ }^{9}$ which would enable learning environments to become more participatory, agentive spaces (Newfield, 2011) would be one way of beginning to address these challenges. As Newfield (2011) comments, teachers could use multimodality in productive, expressive and creative ways that work against deficit models of children and draw on their everyday experiences and language resources. Multimodal pedagogy could enable children whose home language is not the language of learning and teaching (LoLt) to make meaning through their interpretation of other genres of representation employed by the teacher. The children themselves could employ these other genres such as using their body as a key instrument of expression. In short, in South Africa's multilingual classroom realities multimodal pedagogy could become one way of overcoming possible spoken language barriers. 
In addition, the informal nature of ECE beckons creativity, and multi-modal pedagogy could provide a context for a range of communicative acts that enhance learning. We argue that such communicative acts could become an inherent part of a pedagogy of play where play is sustained through reciprocal and responsive relationships (Wood, 2009).

Storytelling, for example, could lend itself to a multimodal approach. The book Not so fast Songololo by Niki Daly could be successfully told through the medium of English to a group of multilingual children. Appropriate story aids, correctly sequenced, could help children identify specific characters and important aspects of the narration. Meaning could be further enhanced through the teacher's use of bodily movements, gestures and sounds. After the story has been presented, children could be given more opportunities to deepen their understandings of the text through a movement or dramatisation ring.

This story also presents many opportunities for vocabulary enrichment. It contains, for example, words such as old and young (as in people), push and pull, in front of and behind. The teacher's use of a bodily kinaesthetic approach to learning would aid meaning making in this context. The example we have just set out would then meet two sets of criteria. It is play based, purposeful, meaningful and reciprocal which are some of the criteria of a pedagogy of play. It is also using the body and the senses to make meaning through a multimodal approach. As Kress (2000) notes, the role of the body and of the senses in semiosis (the process of meaning making through signs) guarantees the multimodality of our semiotic world.

By recommending this approach as part of a pedagogy of play we are not detracting from the enormity of the challenges emanating from South Africa's linguistic landscape. We are just suggesting one possible way for teachers to address multilingual issues in his/her ECE class. Multimodality then is one way of making the 'invisible' visible.

The notion of 'invisible', in this instance, 'invisible' pathways to literacy through a pedagogy of play, is the main focus of this paper and the focus to which we now return in the context of handwriting.

In our earlier example of the acquisition of handwriting and the essential underpinning skills, it became clear that teachers ought to offer a variety of activities to enable children to master the formal skill of handwriting when they enter Grade 1. Gross motor skills are developed through outdoor free play, for example, climbing on jungle gyms, digging in sandpits, painting on an easel to develop the muscles of the shoulder girdle. Fine motor skills are refined through play with construction toys, such as blocks or lego's, manipulative toys such as jigsaw puzzles, other small toys such as peg boards, cars and dolls house furniture, opportunities to thread beads and lace cards, as well as to mould using play dough or clay, and to draw and paint. Zipping, buttoning and using scissors, crayons and other art materials help develop finger dexterity. According to Charlesworth (2004), once a child has attained small muscle (fine motor) skills they can co-ordinate hand and eye. By observing a child drawing it 
is possible to ascertain whether the child is able to make the necessary basic strokes needed for writing.

As already mentioned, handwriting also involves perceptual skills. Children need to perceive similarities and differences, shapes, sizes and directions. These skills are developed through motor movements during free play; climbing on a jungle gym, riding a tricycle, playing a variety of educational games such as memory game, lotto or dominoes or through socio-dramatic play (which, according to Vygotsky, should be the lead activity for children between the ages of three to six years (Karpov, 2001). Through structured teacher-guided activities, such as movement and music rings, children are encouraged to further explore and develop these skills. Finally, in order to write children need to have orientation to printed language. Children, therefore, need opportunities to be creative; to make books and greeting cards during creative art and to be exposed to books and stories in both their mother tongue and the LoLT. This is another instance where a multimodal approach could enrich the communicational and educational landscape.

We also know that children do not develop the ability to write in isolation from the other language skills, namely; listening, speaking and reading (Heilman, Blair \& Rupley, 1994). Hence children need to be immersed in a language rich environment where they experience plenty of opportunities to both hear and talk. The richer the child's linguistic resources, the more readily the skills of reading and writing are acquired. As Anderson, Heibert, Scott and Wilkinson in Heilman et al. (1994, p. 12) claim:

Reading instruction builds especially on oral language. If this foundation is weak, progress in reading will be slow and uncertain. Children must have at least a basic vocabulary, a reasonable range of knowledge about the world around them and the ability to talk about their knowledge. These abilities form the basis for comprehending text.

In short, the acquisition of literacy is a complex, multifaceted process. Literacy skills are not acquired in isolated parts, which Heilman et al. (1994) suggest is the focus of many beginning reading and writing programmes. Literacy skills are best acquired when the child is immersed in a challenging and stimulating environment that provides rich and varied learning experiences, which optimise the child's learning potential. One way to address 'all aspects' is through a pedagogy of play.

\section{Conclusion}

In this paper we argued that the building blocks of literacy are best acquired through a quality play-based approach towards ECE, which is realised in a pedagogy of play. In bringing together two constructs ('pedagogy' and 'play') once seen as disparate we propose a literacy approach that fans, through movement and other activities, perceptual-motor behaviours and sensorimotor integration in a pedagogy of play. Perceptual-motor behaviours and sensorimotor integration are the 'invisible' pathways to literacy. The stimulation of these invisible pathways presents spontaneously during the preschool day. Literacy events to use Heath's term (in Whitehead, 2010) can be structured, like a story ring, or arise unheralded during socio-dramatic or other forms 
of free play. It is the teacher and his/her insight into literacy and its many forms that can make the difference.

It is envisaged that by 2014 all our children in South Africa will be offered the opportunity of a Grade R year before the start of formal schooling. Are our teachers ready for this challenge? An ECE/Grade $\mathrm{R}$ teacher who understands the role of the invisible pathways and how these can be fanned in a pedagogy of play is ideally positioned to optimise incidental and other teaching and learning opportunities. In so doing $s /$ he paves the road to literacy and enables children to develop the KSAVs that not only underpin successful literacy learning but academic learning in general.

\section{Endnotes}

1. Perceptual-motor development is the term, which refers to the development of specific skills and concepts acquired when children take in information from the environment via the senses, interpret this information in the brain and respond to it through movement.

2. Sensorimotor integration refers to the ability to integrate different perceptual-motor behaviour; it is the process of organising sensory input (sensations) so that the brain can produce a meaningful body response.

3. This input could be, for example, in relation to size, shape, speed, space and feelings about one's own body.

4. The vertical midline refers to an imaginary line dividing the body in half (vertically) a left and right side. The horizontal midline refers to an imaginary line dividing the body in half along a horizontal plane.

5. Perception is the brain's interpretation of physical sensations. Sensation is what happens when physical stimuli are translated into neural impulses that can then be transmitted to the brain and interpreted (Lefrancois, 1992 in Charlesworth, 2004, p. 39).

6. Certain forms of play, for instance a home corner in socio-dramatic play, could exclude boys because of gender bias arising out of cultural norms.

7. Mediated or teachable moments refer to opportunities for teacher intervention that occur spontaneously during free play and ring time. A teacher, for example, can observe play in the fantasy corner and purposely intervene to enrich vocabulary use.

8. Free play, routines and rings comprise the three main elements of the preschool programme. Routines are those everyday activities that give structure to the day such as toilet and snack times. They provide excellent opportunities for incidental learning. Free play, also called child-initiated learning, refers to those times when children take responsibility for their own learning through exploration and discovery supported by free choice activities. In a pedagogy of play, the teacher would, where appropriate, mediate learning and engage children in the co-construction of knowledge. Rings refer to teacher-guided activities and are those times when the teacher structures the learning opportunities. Rings include morning discussions, story, movement, music, science and perception. These rings all offer opportunities for literacy acquisition.

9. Multimodality is a theory of meaning and communication. Multimodal pedagogies exemplified here are a move away from the traditional monomodal approaches to teaching and learning with their focus on language as the primary mode of learning. Multimodal pedagogies consider the inclusion of more concrete, material, sensory and bodily practices. They are founded on the idea that meanings are made, disseminated and interpreted through many representational resources or modes, of which language is but one amongst 
many; image, sound, gesture, space, music, movement, facial gestures and body postures (Newfield, 2011).

\section{References}

Anning, A., Cullen, J. \& Fleer, M. (2009). Early childhood education: Society and culture. London: Sage.

Arnheim, D.D. \& Pestolesi, R.A. (1978). Elementary physical education: A developmental approach. St Louis: Mosby.

Ayers, A.J. (2005). Sensory integration and the child. Los Angeles: Western Psychological Services.

Bransford, J.D., Brown, A.L. \& Cocking, R.R. (Eds.). (1999). How people learn. Washington: National Academy of Sciences.

Charlesworth, R. (2004). Understanding child development. (6 $6^{\text {th }}$ ed.). New York: Delmar.

Crain, W. (2005). Theories of development. Concepts and applications. (5 ${ }^{\text {th }}$ ed.). New York: Pearson Education International.

Dahlberg, G., Moss, P. \& Pence, A. (1999). Beyond quality in early childhood education and care: Postmodern perspectives. London: Falmer Press.

Gabbard, C.P. (2008). Lifelong motor development. New York: Pearson Publications.

Gallahue, D.L. Werner, P. \& Luedke, G.C. (1975). Approaches to moving and learning. New York: John Wiley.

Gallahue, D.L. (1982). Understanding motor development in children. New York: John Wiley.

Gallahue, D.L. \& Ozmun, J. (1998). Understanding motor development. Boston: McGraw-Hill.

Gallahue, D.L. \& Donnelly, P.L. (2003). Developmental physical education for all children. Champaign, Illinois: Human Kinetics.

Gerhardt, L.A. (1973). Moving and knowing. Englewood Cliffs: Prentice Hall.

Gordon, A.M. \& Browne, K.W. (2008). Beginnings and beyond: Foundations in early childhood education. ( $8^{\text {th }}$ ed.). New York: Thomson Delmar.

Heilman, A.W., Blair, T.R. \& Rupley, W.H. (1994). Principles and practices of teaching. New York: Merrill.

Hill, S. (2006). Developing early literacy. Assessment and teaching. Victoria: Eleanor Curtain Publishing.

Isbell, C. \& Isbell, R. (2007). Sensory integration. A guide for preschool teachers. Beltsville MD: Gryphon House.

Karpov, Y. (2005). The neo Vygotskian approach to child development. New York: Cambridge University Press.

Kranowitz, C.S. (1998). The out-of-sync child. New York: The Berkley Group. 
Lundsteen, S.W. \& Tarrow, N.B. (1981). Guiding young children's learning. New York: McGraw Hill.

Larson, J. \& Marsh, J. (2005). Making literacy real: Theories and practices for teaching and learning. London: Sage.

Mac Naughton, G. (2003). Shaping early childhood. Berkshire: Open University Press.

Moyles, J. (1989). Just playing? The role and status of play in early childhood education. Maidenhead: Open University Press.

Moyles, J. (1994). The excellence of play. Buckinghamshire: Open University Press.

Newfield, D. (2011). Multimodality and children's participation in classrooms: Instances of research. Perspectives in Education, 29(1), 27-35.

Pellegrini, A.D. (1991). Applied child study. A developmental approach. (2 ${ }^{\text {nd }}$ ed.). New Jersey: Lawrence Erlbaum Associates.

Penn, H. (2008). Understanding early childhood: Issues and controversies. McGraw Hill: Open University Press.

Pramling-Samuelsson, I. (2005). Can play and learning be integrated in a goal-orientated early childhood education? Early Childhood Practice: The Journal for MultiProfessional Partnerships, 7(1), 5-22.

Pramling Samuelsson, I. \& Carlsson, M.A. (2008). The playing learning child. Scandinavian Journal of Educational research, 52(6), 623-641.

Riley, J. (2003). Learning in the early years. London: Paul Chapman Publishing.

Robinson, L.E. \& Goodway, J.D. (2009). Instructional climates in preschool children who are at-risk. Part I: Object-control skill development. Research Quarterly for Exercise and Sport, 80(3), 533-542.

Rogers, S. (2011). Play and pedagogy. In S. Rogers (Ed.). Rethinking play and pedagogy in early childhood education: Concepts, contexts and cultures. London: Routledge.

Spodek, B., Saracho, O.N. \& Davis, M.D. (1991). Foundations of early childhood education. New Jersey: Prentice Hall.

SAIDE (South African Institute for Distance Education). (2010). Grade R Research Project. Braamfontein: SAIDE.

Vygotsky, L. (1978). Mind and society. The development of higher mental processes. Cambridge MS. Harvard University Press.

Whitehead, M. (2010). Language and literacy in the early years 0-7. London: Sage.

Wits School of Education. (2009). Implementation of the National Curriculum Statement in the Foundation Phase. Johannesburg: WSoE.

Wood, E. (2009). Developing a pedagogy of play. In A. Anning, J. Cullen and M. Fleer (eds.). Early childhood education: Society and culture, p. 27-38. London: Sage. 